\title{
Blood Levels and Renal Effects of Atrial Natriuretic Peptide in Normal Man
}

\author{
Peter Weidmann, Loretta Hasler, Markus P. Gnädinger, Rudolf E. Lang, Dominik E. Uehlinger, \\ Sidney Shaw, Wolfgang Rascher, and François C. Reubi \\ Medizinische Poliklinik, University of Berne, CH-3010 Berne, Switzerland; and Department of Pharmacology, University of Heidelberg, \\ Heidelberg, Federal Republic of Germany
}

\begin{abstract}
Since mammalian atria were recently found to contain vasoactive and natriuretic peptides, we investigated the following in normal humans: plasma human atrial natriuretic peptide concentrations, effective renal plasma flow (ERPF), glomerular filtration rate (GFR), urinary water and electrolyte excretion, blood pressure (BP), and catecholamine, antidiuretic hormone (ADH), angiotensin II, and aldosterone levels before, during, and after intravenous administration of the newly synthetized alpha-human atrial natriuretic peptide ( $\alpha$ hANP).

In 10 subjects $\alpha$ hANP given as an initial bolus of $50 \mu \mathrm{g}$ followed by a $45-\mathrm{min}$ maintenance infusion at $6.25 \mu \mathrm{g} / \mathrm{min}(a)$ increased plasma $\alpha$ hANP from $58 \pm 12$ to $625 \pm 87$ (mean \pm SEM) $\mathrm{pg} / \mathrm{ml}$; (b) caused an acute fall in diastolic BP $(-12 \%, P$ $<0.001$ ) and a hemoconcentration (hematocrit $+7 \%, P<0.01$ ) not fully explained by a negative body fluid balance; $(c)$ increased GFR $(+15 \%, P<0.05)$ despite unchanged or decreased ERPF (filtration fraction $+37 \%, P<0.001)$; $(d)$ augmented $(P<0.05-$ $<0.001)$ urinary chloride $(+317 \%)$, sodium $(+224 \%)$, calcium $(+158 \%)$, magnesium $(+110 \%)$, phosphate excretion $(+88 \%)$, and free water clearance (from -0.76 to $+2.23 \mathrm{ml} / \mathrm{min}, P$ $<0.001)$ with only little change in potassium excretion; and $(e)$ increased plasma norepinephrine $(P<0.001)$ while plasma and urinary epinephrine and dopamine, and plasma $\mathrm{ADH}$, angiotensin II, and aldosterone levels were unchanged. The magnitude and pattern of electrolyte and water excretion during $\alpha$ hANP infusion could not be accounted for by increased GFR alone.

Therefore, in normal man, endogenous $\alpha$ hANP seems to circulate in blood. $\alpha$ hANP can cause a BP reduction and hemoconcentration which occur, at least in part, independently of diuresis and are accompanied by sympathetic activation. An increase in GFR that occurs in the presence of unchanged or even decreased total renal blood flow is an important but not sole mechanism of natriuresis and diuresis induced by $\alpha$ hANP in man.
\end{abstract}

\section{Introduction}

Cardiac atria of several species, including man, contain a group of peptides with vasorelaxant, blood pressure (BP) ${ }^{1}$-lowering,

Address correspondence to Dr. Weidmann, Medizinische UniversitätsPoliklinik, Freiburgstrasse 3, CH-3010 Berne, Switzerland.

Received for publication 5 July 1985.

1. Abbreviations used in this paper: $\mathrm{ADH}$, antidiuretic hormone; $\mathrm{ANP}$, atrial natriuretic peptide(s); BP, blood pressure; ERFP, effective renal plasma flow; FF, filtration fraction; GFR, glomerular filtration rate; $\alpha$ hANP, alpha-human atrial natriuretic peptide; PAH, paraamino hippuric acid.

J. Clin. Invest.

(c) The American Society for Clinical Investigation, Inc.

0021-9738/86/03/0734/09 \$1.00

Volume 77, March 1986, 734-742 and natriuretic properties (1-10). The possibility of a physiological role of atrial natriuretic peptide(s) (ANP) in the regulation of sodium fluid volume homeostasis is supported by altered granularity of cardiocytes (11) and atrial contents of natriuretic factor (12) in response to variations in hydration, and by the presence of measurable ANP levels, which are increased by acute saline loading, in the circulation of the rat (13). Effects of ANP on kidney function have been evaluated in experimental animals. Micropuncture studies were interpreted as evidence for a renal tubular action of atrial extracts, with inhibition of sodium reabsorption along the medullary collecting ducts in the presence of an unchanged glomerular filtration rate (GFR) $(14,15)$. However, while GFR was apparently unaltered in the unsteady state after single-dose injection $(1,15-18)$, distinct increases in GFR and, thus, filtered loads of sodium, were noted during a constant infusion of rat atrial extract or synthetic ANP in the isolated kidney $(19,20)$ and in some $(21-23)$, but not all $(24)$, studies in the intact rat or dog. On the other hand, total renal blood flow was variably reported as increased $(20,25,26)$, unchanged $(16$, 22-24), or after an initial rise, even decreased (21). An intrarenal shift of blood flow from the outer to the inner cortex and medulla was also described $(12,25)$ and considered to contribute to ANPinduced sodium diuresis via washout of urea in the papilla.

Whether ANPs are released into the human circulation and whether they may modify renal function in man has been unknown. Therefore, we investigated plasma ANP concentrations, effective renal plasma flow (ERPF), GFR, urinary excretion of water and various electrolytes, blood levels of renin, angiotensin II, aldosterone, antidiuretic hormone, catecholamines, and BP before, during, and after a constant infusion of the alpha-human atrial natriuretic peptide ( $\alpha \mathrm{hANP}$ ) in normal man. The newly synthetized $\alpha$ hANP (Bissendorf Peptide GmbH, Wedemark, Federal Republic of Germany) is the synthetic replicate of the 28-residue active peptide $(3,082.6 \mathrm{~mol} \mathrm{wt})$ at the $\mathrm{COOH}$-terminal end of $\gamma \mathrm{hANP}(13,000 \mathrm{~mol} \mathrm{wt})$.

\section{Methods}

Study A. 10 normal subjects (five women, five men) aged 23-29 yr (mean $\pm \mathrm{SD}, 26 \pm 1.9 \mathrm{yr}$ ) were studied. They were healthy volunteers with a BP consistently $<140 / 90 \mathrm{mmHg}$ and no evidence of any disease. None of the subjects were taking any drugs. Nicotine and alcohol abusers were excluded. After having given their written informed consent to the study, they were instructed to eat a normal diet, avoiding very low or high salt intakes (27) for at least $5 \mathrm{~d}$ before the study.

The following procedure was then performed: a 24-h urine was collected for determinations of sodium, chloride, potassium, calcium, magnesium, phosphate, uric acid, urea and creatinine excretion rates, and osmolality. At the completion of the urine collection, renal function and a variety of additional factors were evaluated under steady state conditions in the supine position. The subjects fasted overnight for $12 \mathrm{~h}$, but a minibreakfast including $200 \mathrm{ml}$ of water or nonsweetened lime blossom tea and $60 \mathrm{~g}$ of bread without any addition was allowed to be taken before 7 a.m. At 7:30 a.m. a bladder catheter was placed and plastic cannulas 
were inserted on each arm into an antecubital vein. GFR and ERPF were determined by constant infusion clearance technique, using ${ }^{51} \mathrm{Cr}$ EDTA and paraamino hippuric acid (PAH), respectively (28). At 8 a.m. an intravenous priming dose of $25 \mu \mathrm{Ci}{ }^{51} \mathrm{Cr}$-EDTA and $0.6 \mathrm{~g} \mathrm{PAH}$ in $50 \mathrm{ml} \mathrm{NaCl}(0.9 \%)$ was administered, followed by a maintenance infusion of a solution containing $7.5 \mu \mathrm{Ci}{ }^{51} \mathrm{Cr}$-EDTA and $0.4 \mathrm{~g} \mathrm{PAH} / 100 \mathrm{ml}$ $\mathrm{NaCl}$ by a calibrated pump (infusion type 5094, Steril Catgut Gesellschaft, Neuhausen, Switzerland) at a rate of $3 \mathrm{ml} / \mathrm{min}$. For blood sampling, the venous access on the contralateral arm was used and blood was allowed to drip freely whenever possible. Urine sampling was obtained by catheter and rinsing with air as well as distilled water, $20 \mathrm{ml}$ twice per urine collection. Urine produced during an initial 45 -min equilibration period was discarded. Starting at 8:45 a.m., two urine collection periods served as control phase. During the $45 \mathrm{~min}$ of clearance periods 3-5, $\alpha$ hANP was infused intravenously ( $\alpha$ hANP infusion phase). A bolus injection of $50 \mu \mathrm{g} \alpha \mathrm{hANP}$ in $1 \mathrm{ml} 0.9 \% \mathrm{NaCl}$ was followed by a maintenance infusion at a rate of $6.25 \mu \mathrm{g} / \mathrm{min}$ (on average $0.1 \mu \mathrm{g} / \mathrm{min}$ per kilogram body weight, which in the subjects ranged from 50 to $80 \mathrm{~kg}$ ); the infusion solution (300 $\mu \mathrm{g} \alpha \mathrm{hANP}$ in $45 \mathrm{ml} 0.9 \%$ and $3 \mathrm{ml} 20 \%$ human serum albumin) was delivered by a calibrated pump (Perfusor V; B. Braun Apparatebau, Melsungen, Federal Republic of Germany). No $\alpha$ hANP was infused during clearance periods 6-8 (recovery phase). $17 \mathrm{ml}$ of $20 \%$ human serum albumin were infused slowly during periods 6 and 7 to limit the tendency for hypovolemia due to blood sampling ( $270 \mathrm{ml}$ up to period 7, $330 \mathrm{ml}$ up to period 8).

Body weight was recorded before and at completion of the test. BP and heart rate were obtained at 1-3-min intervals during clearance periods 3,4 , and 6 , and at 2-5-min intervals during periods $1,2,5,7$, and 8 . Hematocrit, plasma protein, urine volume and $\mathrm{pH}$, and plasma and urinary sodium, chloride, potassium, calcium, magnesium, phosphate, osmolality, uric acid, urea, creatinine, ${ }^{51} \mathrm{Cr}$-EDTA, and PAH values were measured in each clearance period. Plasma renin activity, angiotensin II, aldosterone, norepinephrine, epinephrine, dopamine, and antidiuretic hormone (ADH) levels were determined in clearance periods 2 (control value), 5 (end of $\alpha$ hANP infusion), and 8 (end of recovery phase); while plasma $\alpha$ hANP concentrations were measured in clearance periods 2 and 5-8.

Study B. Three normal men aged 30 yr were studied. Criteria for inclusion and exclusion were similar to those used in Study A. The study protocol was also identical, except that a double dose of $\alpha$ hANP was administered, specifically, an intravenous bolus of $100 \mu \mathrm{g}$ at the beginning of clearance period 3, followed by a maintenance dose of $12.5 \mu \mathrm{g} / \mathrm{min}$ until the end of clearance period 5. Body weight in these subjects ranged from 65 to $80 \mathrm{~kg}$.

Analytical methods. BP was determined with standard cuff and the semiautomatic recorder Sphygmo-Digital (Asulab, Neuchâtel, Switzerland); the mean reading over 7.5-min intervals (half a clearance period) was used for analyses. Hematocrit was measured by the microcrit method, plasma and urinary ${ }^{51} \mathrm{Cr}$ activity in a $\gamma$-counter (Tri-Crab-Scintillation spectrometer; Packard Instrument Co., Downers Grove, IL), PAH by standard photometric method, sodium and potassium by flame photometer, and chloride, calcium, magnesium, phosphate, uric acid, urea, and creatinine by autoanalyzer (Greiner Societé Anonyme, Langenthal, Switzerland). Osmolality was measured by freezing point depression using a cryoscope with Peltier's element, plasma protein by the biuret method, and plasma renin activity, angiotensin II, and aldosterone levels by radioimmunoassay (29-31), as reported previously from our laboratory $(27,32)$. Plasma and urinary norepinephrine, epinephrine, and dopamine were determined with high performance liquid chromatography and electrochemical detection using a modified method of Smedes et al. (33). Plasma ADH levels were measured by radioimmunoassay (34).

Plasma ANP concentrations were determined by a high performance liquid chromatography-radioimmunoassay. Plasma was extracted by passing through ODS-silica cartridges according to the procedure recently described for rat plasma (13). The recovery of synthetic $\alpha$ hANP ranged from 60 to $68 \%$. Radioimmunoassay of ANP was performed using an antibody generated in NZW rabbits immunized with $\alpha$ hANP coupled to bovine thyroglobulin. The standard buffer was $0.1 \mathrm{M}$ Tris buffer, $\mathrm{pH}$
7.4 , containing $0.1 \%$ gelatin. ${ }^{125} \mathrm{I}-\alpha \mathrm{hANP}$ was used as a tracer (Amersham Buchler, Braunschweig, Federal Republic of Germany) and synthetic $\alpha$ hANP (Bachem AG, Bubendorf, Switzerland) was used to construct standard curves. Incubation was carried out for $48 \mathrm{~h}$ at $4^{\circ} \mathrm{C}$. Bound and free ligands were separated by adding dextran-coated charcoal. Using this procedure, the lowest concentration of $\alpha$ hANP yielding a binding significantly different from that in the absence of standard at the $95 \%$ confidence interval was $1.85 \mathrm{pg} /$ tube. The $50 \%$ intercept was at $56 \mathrm{pg} /$ tube. The interassay variation was $14.5 \%(n=6)$, the intraassay variation $6.2 \%(n=10)$. A complete crossreaction was observed with rat atrial peptide ( 28 amino acids, $3,000 \mathrm{~mol} \mathrm{wt}$ ), but not with rat atriopeptin III (Peninsula Laboratories, Belmont, CA). All plasma values were corrected for $62 \%$ recovery.

The filtration fraction (FF) was calculated as the ratio GFR/ERPF; fractional excretion rate as the ratio clearance of excreted parameter/ GFR; and free water clearance as the difference between urinary volume and clearance of osmoles per minute. Statistical analysis was performed with the help of the Statistical Analysis System software package (version OS 82.3, SAS Institute, Inc., Cary, NC). Methods include analysis of variance and Student-Newman-Keuls $t$ test or paired $t$ test for comparison between mean data of different conditions. Values are given as mean \pm SEM. Since natural logarithmic transformation rather than absolute values followed a Gaussian distribution, the natural logarithmic transformation of plasma renin activity, angiotensin II, aldosterone, norepinephrine, epinephrine, dopamine, ADH and $\alpha$ hANP levels, and urinary volume and electrolyte excretion rates was used for statistical analysis.

\section{Results}

\section{Study A}

Plasma $\alpha$ hANP concentrations. The plasma concentration of $\alpha$ hANP in the 10 normal subjects averaged $58 \pm 12 \mathrm{pg} / \mathrm{ml}$ under control conditions, was increased to $625 \pm 87 \mathrm{pg} / \mathrm{ml}$ during $\alpha \mathrm{hANP}$ infusion at a rate of $6.25 \mu \mathrm{g} / \mathrm{min}(P<0.01)$, and rapidly fell thereafter, almost reaching control values at $37.5 \mathrm{~min}$ of the recovery phase (Table I, Fig. 1).

Clinical, some biochemical, and endocrine parameters. Compared with control values, systolic BP was decreased slightly during $\alpha$ hANP infusion (on average $-7 \%$ at the end of the infusion, $P<0.001$ ) and remained at the latter level (around $-7 \%$, $P<0.001$ ) during the recovery phase (Table I, Fig. 2). Diastolic $\mathrm{BP}$ was lowered distinctly during $\alpha$ hANP infusion $(-12 \%$ at the end of the infusion, $P<0.001$ ) and returned partly towards control values during the recovery phase. Heart rate was increased by $10-16 \%$ throughout the $\alpha$ hANP infusion and recovery phase $(P<0.001)$.

Hematocrit and serum protein concentrations rose acutely by an average of $5 \%$ between 0 - and $15-\mathrm{min} \alpha \mathrm{hANP}$ infusion and by $7 \%$ between 15 and $45 \mathrm{~min}$ of infusion; both parameters were restored towards control values at the end of the recovery period (Table I). Based on the changes in hematocrit and plasma protein, the calculated plasma volume $(4.5 \%$ of body weight $=2.79$ liter) fell within $15 \mathrm{~min}$ of $\alpha$ hANP infusion by $140 \mathrm{ml}$ and within $30 \mathrm{~min}$ by $195 \mathrm{ml}$ (removal of whole blood for analytical procedures not considered), while a balanced intra- and extravascular depletion of calculated functional extracellular fluid volume ( $21 \%$ body weight $=13$ liter $)$ would have decreased the latter by $910 \mathrm{ml}$. However, urinary output exceeded intravenous input of normal saline by only $12 \mathrm{ml}$ between 0 and 15 min of $\alpha$ hANP infusion, by $76 \mathrm{ml}$ between 15 and $30 \mathrm{~min}$, and by $57 \mathrm{ml}$ between 30 and $45 \mathrm{~min}$ of this infusion. Urinary output during the entire procedure (on average 0.58 liter) did not exceed input of solutions ( 0.65 liter, see Methods). 
Table I. Clinical, Biochemical, and Endocrine Parameters

Before, During, and After $\alpha$ hANP Infusion at a

Rate of $6.25 \mu \mathrm{g} / \mathrm{min}$ in 10 Normal Subjects (Mean \pm SEM)

\begin{tabular}{|c|c|c|c|}
\hline & \multicolumn{3}{|l|}{ Study phase } \\
\hline & Control $^{*}$ & $\begin{array}{l}\alpha \text { hANP } \\
\text { infusion } \ddagger\end{array}$ & Recoverył \\
\hline \multicolumn{4}{|l|}{ Blood pressure $(\mathrm{mmHg})$} \\
\hline Systolic & $127 \pm 3^{*}$ & $118 \pm 4 \pi$ & $117 \pm 2 \pi$ \\
\hline Diastolic & $87 \pm 2 *$ & $76 \pm 3 \pi$ & $81 \pm 3 \S$ \\
\hline Heart rate $(b p m)$ & $64 \pm 2^{*}$ & $75 \pm 2 \pi$ & $74 \pm 3 \pi$ \\
\hline Body weight ( $k g$ ) & $62.05 \pm 3.4$ & & $61.9 \pm 3.3$ \\
\hline Hematocrit (\%) & $41.6 \pm 1.2^{*}$ & $44.4 \pm 1.0^{\prime \prime}$ & $42.1 \pm 1.3$ \\
\hline \multicolumn{4}{|l|}{ Plasma protein } \\
\hline$(\mathrm{g} / 100 \mathrm{ml})$ & $6.38 \pm 0.10^{*}$ & $6.72 \pm 0.13 \pi$ & $6.46 \pm 0.12$ \\
\hline Plasma $\alpha$ hANP $(p g / m l)$ & $58 \pm 12$ & $625 \pm 87 \pi$ & $80 \pm 18$ \\
\hline \multicolumn{4}{|l|}{ Renin activity } \\
\hline$(n g / m l / h)$ & $1.31 \pm 0.08$ & $1.35 \pm 0.07$ & $1.24 \pm 0.07 \S$ \\
\hline \multicolumn{4}{|l|}{ Angiotensin II } \\
\hline$(p g / m l)$ & $17.2 \pm 1.8$ & $17.0 \pm 1.4$ & $14.5 \pm 1.3$ \\
\hline \multicolumn{4}{|l|}{ Aldosterone } \\
\hline$(n g / 100 m l)$ & $6.8 \pm 1.3$ & $6.3 \pm 1.1$ & $7.5 \pm 1.7$ \\
\hline \multicolumn{4}{|l|}{ Antidiuretic hormone } \\
\hline$(p g / m l)$ & $4.0 \pm 0.4$ & $3.6 \pm 0.5$ & $6.0 \pm 1.2$ \\
\hline \multicolumn{4}{|l|}{ Epinephrine } \\
\hline$(n g / 100 m l)$ & $1.4 \pm 0.2$ & $1.8 \pm 0.4$ & $2.0 \pm 0.3$ \\
\hline \multicolumn{4}{|l|}{ Norepinephrine } \\
\hline$(\mathrm{ng} / 100 \mathrm{ml})$ & $18.7 \pm 0.4$ & $32.3 \pm 3.5^{\prime \prime}$ & $20.8 \pm 6.9$ \\
\hline \multicolumn{4}{|l|}{ Dopamine } \\
\hline$(n g / 100 m l)$ & $1.1 \pm 0.3$ & $1.4 \pm 0.2$ & $1.4 \pm 0.5$ \\
\hline \multicolumn{4}{|l|}{ Urinary epinephrine } \\
\hline$(n g / m i n)$ & $5.7 \pm 0.6$ & $5.9 \pm 0.7$ & $9.3 \pm 1.6$ \\
\hline \multicolumn{4}{|l|}{ Norepinephrine } \\
\hline$(n g / m i n)$ & $29 \pm 3$ & $47 \pm 6$ & $34 \pm 3$ \\
\hline Dopamine (ng/min) & $310 \pm 35$ & $285 \pm 44$ & $343 \pm 53$ \\
\hline
\end{tabular}

* Mean values of clearance periods 1 and 2.

$\ddagger$ Values from clearance periods 5 (end of $\alpha$ hANP infusion) or 8 (end of recovery phase), respectively.

$\S P<0.05$.

" $P<0.01$.

I $P<0.001$ vs. control value. bpm, beats per $\mathrm{min}$.

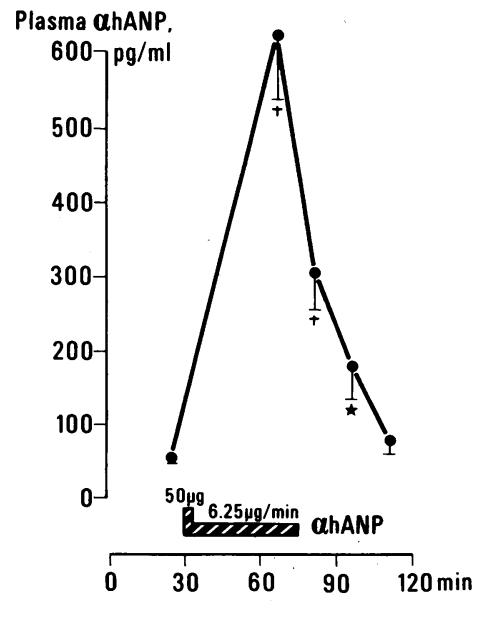

Figure 1. Plasma $\alpha$ hANP concentrations before, during, and after $\alpha$ hANP infusion in normal subjects (mean \pm SEM).

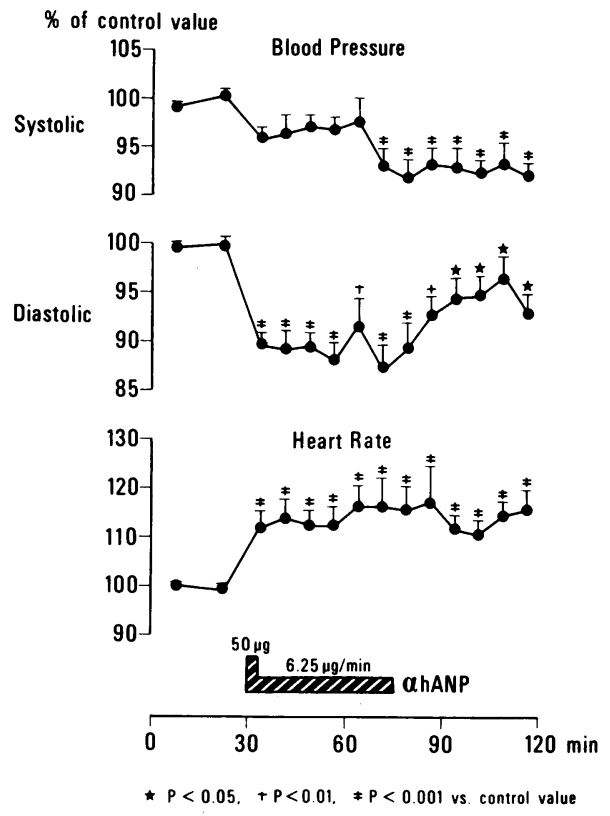

Figure 2. Effect of $\alpha \mathrm{hANP}$, a $50 \mu \mathrm{g}$ bolus followed by maintenance infusion of $6.25 \mu \mathrm{g} / \mathrm{min}$, on BP and heart rate in 10 normal subjects (mean \pm SEM). The mean of the two control values is taken as $100 \%$.

Plasma renin activity, angiotensin II, aldosterone, $\mathrm{ADH}$, epinephrine, and dopamine levels were not significantly modified during the procedure (Table I). Plasma norepinephrine levels were elevated $(P<0.001)$ during $\alpha$ hANP infusion and restored to control values thereafter.

Renal function and plasma and urinary electrolytes. Compared with the mean value of the two control clearance periods, ERPF was not significantly changed during $\alpha$ hANP infusion and decreased $(P<0.05)$ during the first $30 \mathrm{~min}$ of the recovery phase (Table II, Fig. 3). In contrast, GFR was modestly increased ( $+15 \%$ on average, $P<0.05$ ) and FF was markedly increased ( $+37 \%, P<0.001)$ during $\alpha$ hANP infusion. GFR returned completely to control levels and FF almost to control levels during the recovery phase.

Urine flow and sodium, chloride, magnesium, calcium, phosphate, and osmolal excretion rates were increased significantly $(P<0.01$ to $<0.001)$ during $\alpha$ hANP infusion (Table II, Figs. 4 and 5). Maximal percentage increases of absolute excretion rates were $+495 \%$ on average for urine flow, $+317 \%$ for chloride, $+224 \%$ for sodium, $+158 \%$ for calcium, $+110 \%$ for magnesium, and $+88 \%$ for phosphate. Maximal percentage increases of fractional excretion rates were $+261 \%$ for chloride, $+179 \%$ for sodium, $+114 \%$ for calcium, $+75 \%$ for magnesium, and $+75 \%$ for phosphate. Urinary potassium excretion was increased only slightly $(P<0.01,+53 \%)$ during the first $30 \mathrm{~min}$ and was already restored to control levels between 30 and 45 min of $\alpha$ hANP infusion (Fig. 4).

During the two clearance periods between 15 and $45 \mathrm{~min}$ of $\alpha \mathrm{hANP}$ infusion, the mean increases in urine flow rate $(+6.6$ and $5.8 \mathrm{ml} / \mathrm{min}$, respectively) corresponded to 33 and $32 \%$ of the increase in GFR $\left(+20\right.$ and $+18 \mathrm{ml} / \mathrm{min}$ per $\left.1.73 \mathrm{~m}^{2}\right)$. The increases in sodium excretion rate $(+415$ and $+395 \mu \mathrm{mol} / \mathrm{min})$ corresponded to 14.4 and $15.2 \%$ of the increases in filtered load of sodium ( +2880 and $+2590 \mu \mathrm{mol} / \mathrm{min})$; thus, absolute sodium reabsorption increased by +2465 and $+2195 \mu \mathrm{mol} / \mathrm{min}$, re- 
Table II. Renal Function and Electrolyte Excretion Before, During, and After ahANP Infusion at a Rate of $6.25 \mu \mathrm{g} / \mathrm{min}$ in 10 Normal Subjects (Mean \pm SEM)

\begin{tabular}{|c|c|c|c|}
\hline & \multicolumn{3}{|l|}{ Study phase } \\
\hline & Control $^{*}$ & $\begin{array}{l}\alpha \text { hANP } \\
\text { Infusion } \ddagger\end{array}$ & Recoverył \\
\hline \multicolumn{4}{|l|}{$\begin{array}{l}\text { Effective renal plasma } \\
\text { flow }(\mathrm{ml} / \mathrm{min} \text { per }\end{array}$} \\
\hline $\left.1.73 \mathrm{~m}^{2}\right)$ & $676 \pm 41$ & $585 \pm 71$ & $612 \pm 42$ \\
\hline \multicolumn{4}{|l|}{$\begin{array}{l}\text { Glomerular filtration } \\
\text { rate }(\mathrm{ml} / \mathrm{min} \text { per }\end{array}$} \\
\hline $\left.1.73 \mathrm{~m}^{2}\right)$ & $120 \pm 3$ & $138 \pm 12$ & $118 \pm 5$ \\
\hline Filtration fraction $(\%)$ & $18.2 \pm 0.9$ & $24.8 \pm 2.1^{\prime \prime}$ & $19.6 \pm 0.9$ \\
\hline \multicolumn{4}{|l|}{ Urinary excretion rates } \\
\hline $\begin{array}{l}\text { fluid volume } \\
\qquad(\mathrm{ml} / \mathrm{min})\end{array}$ & $2.0 \pm 0.6$ & $7.8 \pm 2.0^{\prime \prime}$ & $1.5 \pm 0.2$ \\
\hline sodium $(\mu \mathrm{mol} / \mathrm{min})$ & $194 \pm 25$ & $588 \pm 188^{\prime \prime}$ & $327 \pm 36^{11}$ \\
\hline FE sodium $(\%)$ & $1.14 \pm 0.16$ & $2.84 \pm 0.77^{\prime \prime}$ & $1.92 \pm 0.19^{\prime \prime}$ \\
\hline chloride $(\mu \mathrm{mol} / \mathrm{min})$ & $162 \pm 30$ & $541 \pm 179^{\|}$ & $285 \pm 39^{\| \prime}$ \\
\hline $\begin{array}{l}\text { FE chloride (\%) } \\
\text { potassium }\end{array}$ & $1.31 \pm 0.23$ & $3.74 \pm 1.07^{\prime \prime}$ & $2.33 \pm 0.29^{\prime \prime}$ \\
\hline$(\mu \mathrm{mol} / \mathrm{min})$ & $68 \pm 10$ & $72 \pm 7$ & $70 \pm 14$ \\
\hline FE potassium (\%) & $15.4 \pm 2.0$ & $13.8 \pm 2.4$ & $15.9 \pm 2.7$ \\
\hline magnesium & & & \\
\hline$(\mu \mathrm{mol} / \mathrm{min})$ & $2.5 \pm 0.3$ & $4.9 \pm 1.2^{\prime \prime}$ & $3.6 \pm 0.4 \S$ \\
\hline FE magnesium (\%) & $2.8 \pm 0.3$ & $4.6 \pm 0.9 \S$ & $4.1 \pm 0.5 \S$ \\
\hline calcium $(\mu \mathrm{mol} / \mathrm{min})$ & $4.0 \pm 0.7$ & $8.9 \pm 2.4^{\prime \prime}$ & $5.9 \pm 0.9 \S$ \\
\hline FE calcium $(\%)$ & $1.57 \pm 0.30$ & $2.93 \pm 0.68^{\prime \prime}$ & $2.40 \pm 0.38 \S$ \\
\hline phosphate & & & \\
\hline$(\mu \mathrm{mol} / \mathrm{min})$ & $5.8 \pm 1.1$ & $9.0 \pm 1.1^{11}$ & $7.4 \pm 0.8 \S$ \\
\hline FE phosphate (\%) & $6.2 \pm 1.0$ & $9.6 \pm 1.1^{11}$ & $9.0 \pm 0.8^{\|}$ \\
\hline uric acid $(\mu \mathrm{mol} / \mathrm{min})$ & $2.7 \pm 0.2$ & $2.7 \pm 0.6$ & $2.3 \pm 0.1$ \\
\hline FE uric acid (\%) & $13.1 \pm 3.9$ & $11.2 \pm 2.1$ & $11.2 \pm 1.8$ \\
\hline urea $(\mu \mathrm{mol} / \mathrm{min})$ & $240 \pm 27$ & $296 \pm 49$ & $225 \pm 23$ \\
\hline FE urea $(\%)$ & $47 \pm 4$ & $50 \pm 5$ & $48 \pm 3$ \\
\hline creatinine & & & \\
\hline$(\mu \mathrm{mol} / \mathrm{min})$ & $8.9 \pm 0.8$ & $8.7 \pm 1.0$ & $8.3 \pm 0.6$ \\
\hline FE creatinine (\%) & $96 \pm 3$ & $86 \pm 4$ & $96 \pm 3$ \\
\hline $\begin{array}{l}\text { osmoles } \\
\qquad(\mathrm{mosmol} / \mathrm{min})\end{array}$ & $0.78 \pm 0.08$ & $1.62 \pm 0.42^{\|}$ & $1.02 \pm 0.10$ \\
\hline $\begin{array}{l}\text { Urinary osmolality } \\
\qquad(\mathrm{mmol} / \text { liter })\end{array}$ & $912 \pm 211$ & $340 \pm 94 \S$ & $823 \pm 215$ \\
\hline $\begin{array}{l}\text { Free water clearance } \\
\qquad(\mathrm{ml} / \mathrm{min})\end{array}$ & $-0.76 \pm 0.57$ & $+2.23 \pm 1.15^{\prime \prime}$ & $-2.15 \pm 0.14$ \\
\hline
\end{tabular}

* Mean values of clearance periods 1 and 2 .

$¥$ Values from clearance periods 5 (end of $\alpha$ hANP infusion) or 8 (end of recovery phase), respectively.

$\S P<0.01$.

" $P<0.001$ vs. control value.

$\mathrm{FE}$, fractional excretion rate.

spectively. The increases in chloride excretion rate $(+345$ and $+380 \mu \mathrm{mol} / \mathrm{min}$ ) corresponded to 16.7 and $20.5 \%$ of the increases in filtered load of chloride $(+2060$ and $+1855 \mu \mathrm{mol} /$ min); thus, absolute chloride reabsorption was increased by +1715 and $+1475 \mu \mathrm{mol} / \mathrm{min}$, respectively.

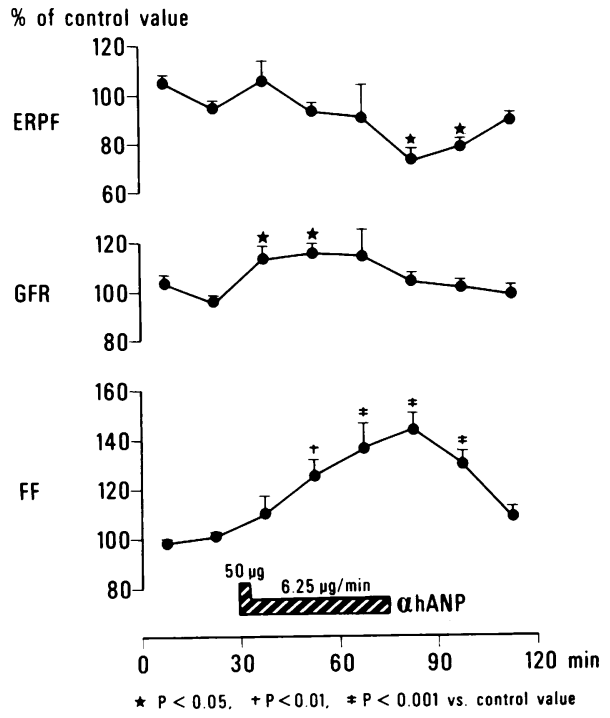

Figure 3. Effect of $\alpha \mathrm{hANP}$, a $50 \mu \mathrm{g}$ bolus followed by maintenance infusion of $6.25 \mu \mathrm{g} / \mathrm{min}$, on renal function in 10 normal subjects (mean \pm SEM). The mean of the two control values is taken as $100 \%$.

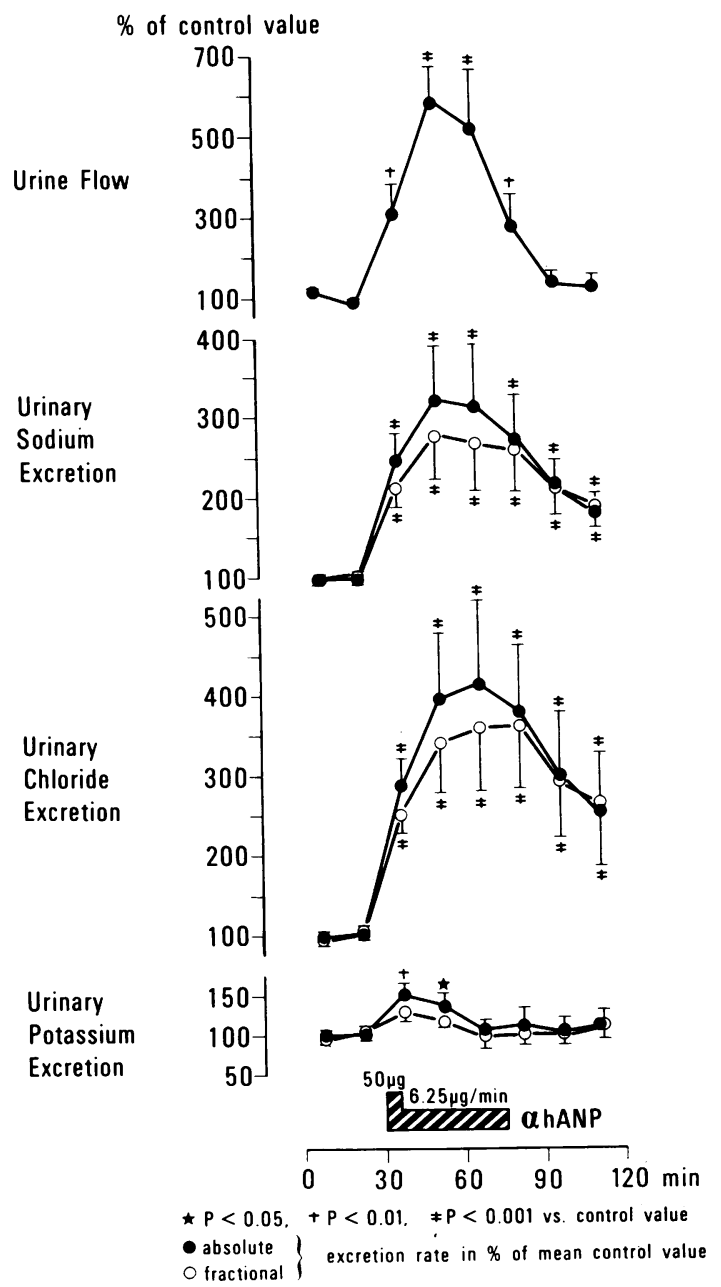

Figure 4. Effect of $\alpha \mathrm{hANP}$, a $50 \mu \mathrm{g}$ bolus followed by maintenance infusion of $6.25 \mu \mathrm{g} / \mathrm{min}$, on urine flow and sodium, chloride and potassium excretion rates in 10 normal subjects (mean \pm SEM). The mean of the two control values is taken as $100 \%$. 


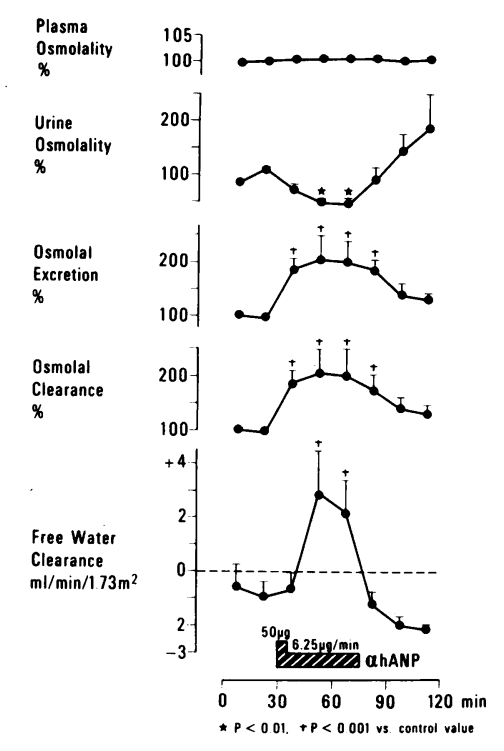

Figure 5. Effect of $\alpha$ hANP, a $50 \mu \mathrm{g}$ bolus followed by maintenance infusion of $6.25 \mu \mathrm{g} / \mathrm{min}$, on plasma and urinary osmolality and the clearances of osmoles and free water in 10 normal subjects (mean \pm SEM). The mean of the two control values is taken as $100 \%$.
Compared with control conditions, urinary osmolality was decreased by $48 \%$ during $\alpha$ hANP infusion $(P<0.01)$, while free water clearance was increased $(P<0.001)$ (Table II, Fig. 5). Urinary $\mathrm{pH}$ tended to rise slightly from $6.87 \pm 0.33$ to $7.32 \pm 0.26$ during the first $15 \mathrm{~min}$ of $\alpha$ hANP infusion; it averaged 6.98 \pm 0.27 and $6.92 \pm 0.26$ during the two subsequent clearance periods with $\alpha$ hANP infusion, and $6.58 \pm 0.34$ or $7.06 \pm 0.48$, respectively, during initial and last periods of the recovery phase (all these values not significantly different from control).

Compared with mean control values of plasma potassium ( $3.6 \pm 0.1 \mathrm{mmol} /$ liter), magnesium $(0.74 \pm 0.02 \mathrm{mmol} /$ liter $)$, and total calcium $(2.13 \pm 0.02 \mathrm{mmol} / \mathrm{liter})$, these variables tended to be increased slightly ( $+2.5 \%$ ) but not significantly during $\alpha$ hANP infusion; plasma phosphate (control value, $0.77 \pm 0.03 \mathrm{mmol} /$ liter) was progressively decreased by $-9 \pm 4 \%$ at the end of $\alpha \mathrm{hANP}$ infusion and by a maximal change of $-13 \pm 4 \%(P<0.05) 22$ min thereafter. Plasma sodium (control value, $144.8 \pm 0.9 \mathrm{mmol} /$ liter), chloride (control value, $102.7 \pm 0.5 \mathrm{mmol} / \mathrm{liter}$ ), and uric acid were not modified.

\section{Study B}

$\alpha$ hANP infusion at a double rate $(12.5 \mu \mathrm{g} / \mathrm{min})$ increased plasma $\alpha$ hANP from a control value of $48 \pm 40^{\circ}$ to $1242 \pm 194 \mathrm{pg} / \mathrm{ml}$; thereafter, plasma $\alpha$ hANP fell rapidly, already reaching control values at $37.5 \mathrm{~min}$ of the recovery phase.

During double-dose $\alpha$ hANP infusion, maximal decreases in diastolic and systolic BP (on average -23 and $-17 \%$; Fig. 6) were also twice those induced by the lower $\alpha$ hANP infusion rate (Fig. 2); heart rate was no longer increased at the time of the greatest fall in BP, despite a preceeding transient increase. Hematocrit and plasma protein concentration rose by $6.5 \pm 4.2 \%$ and $9.0 \pm 2.9 \%$, respectively, and were partly or completely restored towards control values at $37.5 \mathrm{~min}$ of the recovery phase $(103 \pm 1.5$ and $101 \pm 1.5 \%$ of control values, respectively). Urinary output during the entire procedure (on average 0.41 liter) was slightly below total input of solutions ( 0.61 liter, see Methods); mean body weight increased correspondingly from 73.2 to $73.3 \mathrm{~kg}$.

GFR and ERPF decreased progressively during $\alpha$ hANP infusion ( $-35 \pm 22 \%$ and $-46 \pm 20 \%$, respectively; Fig. 7); during the recovery phase, ERPF and BP were partly and GFR was fully restored to control values. FF was increased by $32 \pm 6 \%$
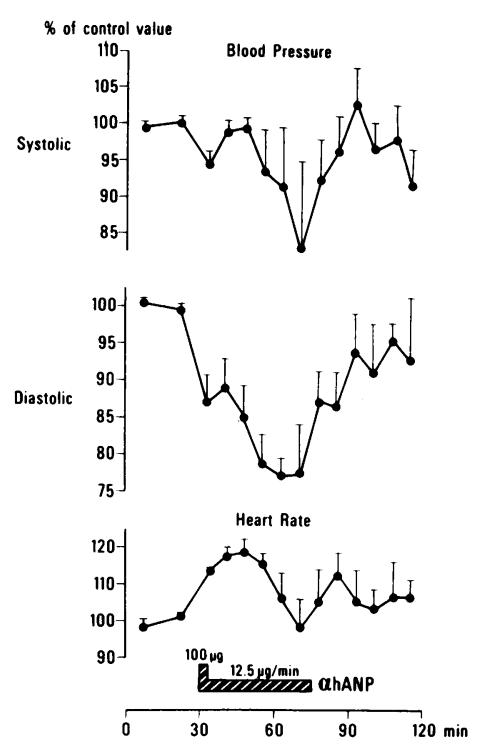

Figure 6. Effect of $\alpha$ hANP, a $100 \mu \mathrm{g}$ bolus followed by maintenance infusion of $12.5 \mu \mathrm{g} / \mathrm{min}$, on BP and heart rate in three normal subjects (mean \pm SEM). The mean of the two control values is taken as $100 \%$.

during the $\alpha$ hANP infusion and by $25 \pm 3 \%$ at the end of the recovery phase.

During double-dose $\alpha$ hANP infusion, maximal percentage changes in absolute excretion rates of volume (on average $+333 \pm 140 \%)$, sodium $(+273 \pm 51 \%$; Fig. 7$)$, chloride $(+326 \pm 57 \%)$, potassium $(+90 \pm 9 \%)$, magnesium $(+89 \pm 28 \%)$, calcium $(+129 \pm 41 \%)$, and phosphate $(+42 \pm 8 \%)$ did not exceed those produced by the lower $\alpha$ hANP infusion rate; moreover, maximal urinary excretion rates during double-dose infusion were limited to the first $30 \mathrm{~min}$ and subsequently fell back to control values during the last $15 \mathrm{~min}$ of infusion (Fig. 7). Changes in urinary osmolality were quite similar to those obtained with the lower $\alpha$ hANP infusion rate, while free water clearance again tended to be increased (Fig. 7).

Side effects. Nausea accompanying marked decreases in BP with unchanged or even slowed heart rate occurred during the last $15 \mathrm{~min}$ of $\alpha \mathrm{hANP}$ infusion or early in the recovery phase in three subjects in study A and in one subject in study B. Transient facial flushing developed in one subject after the initial bolus injection in study $B$.

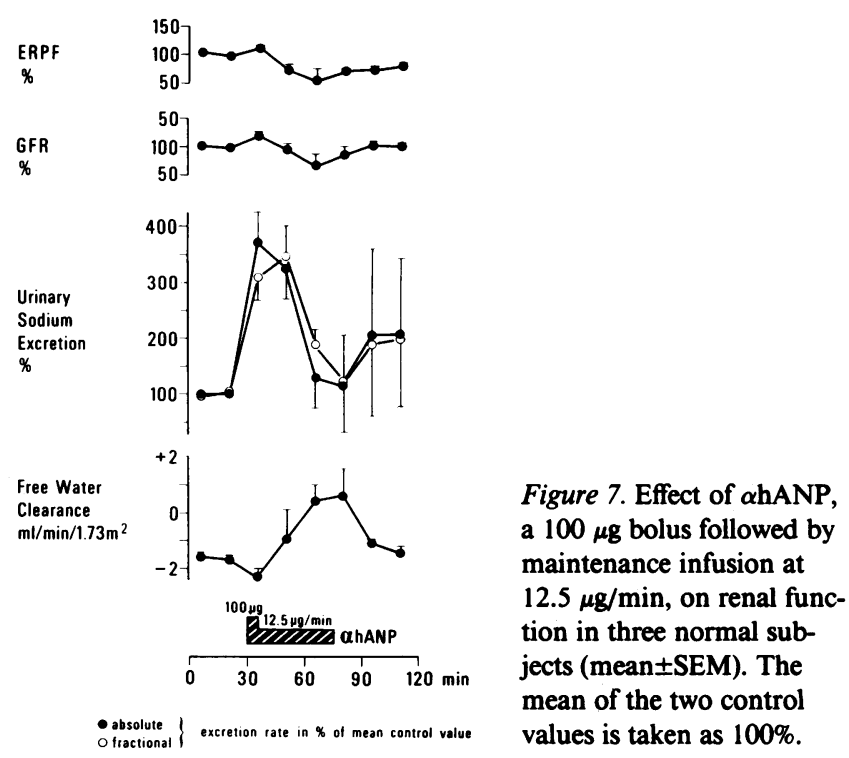




\section{Discussion}

The findings of the present study demonstrate that in normal man, atrial natriuretic peptide(s) circulate in distinct concentrations in blood; while an increase in plasma $\alpha$ hANP concentrations, induced by intravenous infusion of synthetic $\alpha$ hANP, lowered diastolic $(P<0.001)$, and to a lesser extent systolic $(P$ $<0.01)$ BP, increased GFR $(P<0.05)$ and markedly enhanced the renal excretion of various electrolytes and water.

The material measured by radioimmunoassay in the plasma of our healthy volunteers seems either identical with or very closely related to $\alpha$ hANP. The serial dilution of extracts from plasma inhibited the binding of ${ }^{125} \mathrm{I}-\alpha \mathrm{hANP}$ to the antiserum parallel to the standard curve of $\alpha$ hANP. When plasma was subjected to gel chromatography, a major peak of immunoreactive material eluted at the position of an apparent molecular weight of 3,000 which roughly corresponds to that of $\alpha$ hANP. The validity of the radioimmunoassay is corroborated by the consistent marked increases in plasma $\alpha$ hANP concentrations measured during $\alpha$ hANP infusion. Therefore, the endogenous blood levels detected by this radioimmunoassay in our normal subjects may well reflect an ongoing secretion of $\alpha$ hANP during conditions of unrestricted sodium intake from the human heart. Peptides of human atrial origin have been isolated, characterized, and synthetized (7). The short half-life of plasma $\alpha$ hANP, as evidenced by the rapid fall of plasma concentrations after discontinuation of $\alpha \mathrm{hANP}$, suggests that the endogenous blood levels in normal man can be maintained only by a similar efficient rate of secretion or production. The role of the heart as an endocrine gland which provides the human circulation with ANP is supported by the recent demonstration of an identical ANP released from heart tissue and present in the plasma of rats (13) or coronary venous effluent of rabbit or rat heart (35-37). The possibility of a production in extracardiac tissue such as brain $(37,38)$ must also be considered. Nevertheless, isolation from plasma and sequencing of the peptide will be required for a definite clarification of the structure of circulating hANP.

The acute fall (10\% or more) in diastolic BP within the first minutes of single bolus injection $(9,10)$ and constant infusion of $\alpha$ hANP in initially well-hydrated normotensive subjects points to a potent cardiovascular action of $\alpha$ hANP in normal man. A similar rapidity of the BP-lowering effect of ANP in experimental animals, its persistence in the anephric state (12), and an acute decrease in total peripheral vascular resistance $(25,39)$ also indicated that overall body sodium fluid volume depletion is not required as a mechanism. The smooth muscle cells of rat and rabbit aorta contain specific receptors for $\operatorname{ANP}(40,41)$, and the latter activates particulate guanylate cyclase which, in turn, elevates cyclic guanosine monophosphate in vascular smooth muscle (42). In aortic or renal artery preparations of rat, rabbit, or dog, atrial extracts or peptides were reported to antagonize the vasoconstrictor effect of both norepinephrine and angiotensin II $(5,6,19,20,43,44)$. !n normal man, however, $\alpha$ hANP acutely counteracted the pressor action of norepinephrine more than that of angiotensin II (9). This suggests that $\alpha$ hANP may, at least in humans, interact preferentially with noradrenergic cardiovascular control.

Intravascular volume contraction is probably a complementary factor in the BP-lowering mechanism of $\alpha$ hANP. However, although $\alpha \mathrm{hANP}$ infusion at a rate of $6.25 \mu \mathrm{g} / \mathrm{min}$ (study A) was associated with a net negative body fluid balance of $235 \mathrm{ml}$, the initial decrease in BP occurred before a relevant extracellular fluid depletion $(-20 \mathrm{ml}$ whole blood and $12 \mathrm{ml}$ excess urine output during the first $15 \mathrm{~min}$ ), and fluid balance during the entire test was even slightly positive $(+70 \mathrm{ml})$. Moreover, during the procedure with double-dose $\alpha$ hANP infusion (study B), BP tended to fall even more markedly despite no negative overall fluid balance (+0.20 liter). Considering the corresponding fluid input and output rates, the $6 \%$ or greater rises in hematocrit and plasma protein concentration during $\alpha$ hANP infusion indicate a greater degree of intravascular than overall extracellular fluid volume contraction. The rapid restoration of hematocrit and plasma protein towards control values during the recovery phase also supports the occurrence of a readily reversible extravascular shift of fluid accompanying the $\alpha$ hANP infusion. Such transfer could be due to an increase in capillary permeability and/or filtration pressure.

Whether and to what extent ANP may modify the activity of the sympathetic nervous system has been largely unknown. Plasma norepinephrine levels and heart rate were increased significantly $(P<0.001)$ during $\alpha$ hANP infusion in our normal subjects. Urinary norepinephrine excretion rate also tended to rise, while plasma and urinary epinephrine and dopamine levels were rather stable. This constellation probably reflects baroreflex activation of the efferent sympathetic nerves secondary to the decreases in BP. Thus, regulatory relationships in the normal human may again differ from certain animal experiments in which heart rate in the presence of an acutely lowered BP was unchanged or even decreased $(39,45)$ by atrial extracts or ANP. Nevertheless, four of our normal subjects developed nausea and signs of a vagal reaction towards or shortly after the end of the $\alpha$ hANP infusion, as evidenced by a stable or slowing heart rate despite a marked fall in BP. The latter constellation was particularly evident during the last $15 \mathrm{~min}$ of high dose $\alpha$ hANP infusion in study B. Therefore, variable net chronotropic influences of $\alpha$ hANP may reflect a predominant sympathetic response during shorter or low dose infusion and an inappropriate rise in efferent vagal tone with increased dose and/or duration of infusion. In the rat, atrial extract seems to promote its BP-lowering and a bradycardic effect via afferent vagal fibres which may be activated via chemosensitive cardiopulmonary receptors (39). A direct action on ANP on cardiac tissue is not excluded.

ERPF tended to decrease progressively during $\alpha$ hANP infusion in our normal subjects. A similar trend has been noted in the anesthetized dog or rabbit $(21,46)$, although consistent decreases (22), unchanged values $(16,18,23,24)$, or even dosedependent increases $(1,25,26)$ in total renal blood flow were noted in other animal experiments, some of which were based on injection of rather than constant infusion of ANP. Increasing the $\alpha$ hANP infusion rate from 6.25 to $12.5 \mu \mathrm{g} / \mathrm{min}$ in the normal subjects was accompanied by a greater fall in ERPF. ANP may modify renal perfusion indirectly through the lowered systemic pressure and hemoconcentration; a vasoconstrictor influence of sympathetic activation could also play a mediating role. Furthermore, ANP may directly promote renal vasoconstriction under basal conditions and vasodilation when renal vessels are preconstricted by norepinephrine or angiotensin II $(6,19,20$, 24). Plasma renin and angiotensin II levels were normal in our untreated healthy subjects and not significantly modified during $\alpha$ hANP infusion. The latter could theoretically limit the value of the ERPF estimate by decreasing PAH extraction rate through inhibition of tubular secretion and/or an increase in medullary blood flow $(12,25)$. PAH clearance correctly indicated changes in renal blood flow in dogs receiving an ANP infusion (21), but no measurements of PAH extraction rate were performed in this human study. 
The increase in GFR (on average $+15 \%, P<0.05$ ) despite decreased BP and ERPF, with the FF rising by an impressive $44 \%(P<0.01)$, represents a unique renal action of $\alpha$ hANP in man. It has also been noted in the anesthetized dog $(21,47)$, while an increased GFR without change in total renal blood flow has been observed in the rat $(22,23)$. A constriction of the efferent accompanied by a dilatation of the afferent glomerular arterioles, as suspected during ANP infusion in the isolated rat kidney $(6,20)$, may elevate the glomerular capillary hydraulic pressure and, thus, increase GFR despite the reduction of renal blood flow (48). On the other hand, there is evidence against an increase in the glomerular permeability $(48,49)$ and the reported medullary redistribution of renal blood flow $(12,25)$ may also fail to explain the ANP-induced rise in GFR (23).

The marked increases in urine flow (up to fivefold) and excretion rates of chloride (threefold), sodium (twofold), calcium (1.5-fold), magnesium, and phosphate (both approximately doubled) during $\alpha \mathrm{hANP}$ infusion at $6.25 \mu \mathrm{g} / \mathrm{min}$ in our normal subjects were at least in part due to the distinct rise in the filtered loads of fluid and electrolytes. In fact, only $15 \%$ of the increment in filtered sodium load were excreted, while $85 \%$ were reabsorbed; corresponding values for chloride were 19 and $81 \%$, respectively. The small rise in the fractional excretion rates of sodium and chloride from 1.1 and $1.3 \%$, respectively, during control conditions to about 3.0 and $3.7 \%$ during $\alpha$ hANP infusion in normal humans could possibly be an appropriate consequence of the acutely increased GFR, as recently demonstrated in the rat (23). In the present study, the infusion of $0.9 \% \mathrm{NaCl}$ as carrier solution for PAH, ${ }^{51} \mathrm{Cr}$-EDTA, and $\alpha$ hANP could have favored an exaggeration of the apparent excretory responses to $\alpha$ hANP and a delayed return of excretory parameters to control values during the recovery phase. However, such an influence should have been minimal, since the $\mathrm{NaCl}$ infusion at a rate of $3 \mathrm{ml} / \mathrm{min}$, rather than representing a load, served to prevent sodium fluid volume depletion due to the sampling of blood in closely corresponding amounts.

Free water clearance was increased markedly during $\alpha$ hANP infusion in the normal humans. Although such a tendency was also noted after injection of rat atrial extract into isolated perfused rat kidneys (19), free water clearance was unchanged or even decreased during $\alpha$ hANP infusion in intact rats, dogs, or monkeys $(16,17,21,25,47)$.

How much a given increase in GFR will augment the excretion of water and electrolytes is difficult to judge. Nevertheless, some observations obtained with substances that are not known to have transport inhibitory properties are available. In the dog, infusions of glycine or glucagon increased GFR by 17 and $31 \%$, respectively; sodium excretion was augmented by only 68 and $135 \%$, respectively, although both substances also caused a $20-$ $30 \%$ rise in renal blood flow (50). In man, it is possible to increase GFR without marked changes in BP by hydralazine or pyrogenic substances. Under such circumstances there is a direct linear correlation between the percentage changes in GFR and the concomitant changes in urine flow rate (hydralazine, $n=48, r$ $=0.56, P<0.001, y$ [flow rate] $=3.48 \times-232$; pyrogen, $n$ $=21, r=0.66, P<0.001, y=2.58 \times-143)$ or the changes in urinary sodium excretion (pyrogen, $n=21, r=0.64, P<0.001$, $y$ [sodium excretion] $=2.94 \times-176)($ Reubi, F. C., unpublished observations). According to the calculated relationships, a $15 \%$ increase in GFR, such as observed in the present $\alpha$ hANP experiments of study $\mathrm{A}$, should produce a $54-68 \%$ rise in volume and sodium excretion. These values are quite close to those ob- served during glycine infusion in the $\operatorname{dog}(50)$. It appears therefore, that for a given increase in GFR, $\alpha$ hANP may cause an at least twofold greater natriuresis and diuresis than these other vasoactive substances.

The excretory component in $\alpha$ hANP's action that is not explained by increased GFR alone may be mediated by additional renal hemodynamic, humoral, or even direct tubular effects.

An inner cortical and medullary shift of renal plasma flow $(12,25)$ and a rise in papillary plasma flow $(12)$ were observed after administration of atrial extracts to rats. The resultant washout of urea from the papilla might lead to a disruption of the counter current gradients with reduction of sodium reabsorption in the thick ascending limb of the deep nephrons. The latter sequence of events may have modulated sodium excretion in the normal humans while their ERPF was unchanged or only slightly decreased; while a more marked fall in ERPF such as observed during high dose $\alpha$ hANP infusion may well have minimized or even precluded any relevant natriuresis from medullary hyperperfusion by redistribution. The increased tubular flow rate and urea washout could also account for the dissociation between water and sodium excretion. In fact, the increment in free water clearance lagged behind the rise in sodium and chloride excretion, as evidenced by still unchanged free water clearance despite significantly increased natriuresis and chloruresis $(P<0.001)$ during the initial $15 \mathrm{~min}$ of $\alpha$ hANP infusion. Nevertheless, it is difficult to interpret changes in free water clearance in nonwater-loaded subjects.

Considering humoral factors, blood levels of $\mathrm{ADH}$, aldosterone, and dopamine, as well as urinary dopamine excretion rates were unchanged at 37 min of $\alpha$ hANP infusion in the present study. Nevertheless, circulating aldosterone was reduced in anesthetized dogs (21), and atrial extracts lowered aldosterone production in isolated adrenal cells of rat or other animals (5152). The noradrenergic activation may in some way contribute, since chemical sympathectomy or $\alpha$-receptor blockade diminished the diuretic and natriuretic responses to atrial extract in the rat (53). Moreover, an enhanced production of renal prostaglandin E (54) or kallikrein (55) could play a complementary role and also antagonize the tubular action of $\mathrm{ADH}$.

The present findings do not permit us to delineate or rule out a direct tubular action of $\alpha$ hANP. Micropuncture studies in the rat indicated that sodium reabsorption in accessible segments of superficial nephrons and in Henle's loop is not decreased by atrial extract or $\operatorname{ANP}(14,15,23)$. However, a direct inhibitory influence on more distal sodium reabsorption in the rat was postulated $(14,15,18)$. This concept, as well as the theoretical possibilities of altered peritubular Starling forces, an enhanced permeability of collecting ducts with a resultant net transfer of sodium from the interstitium to duct fluid, an interference of $\alpha$ hANP with the tubular action of $\mathrm{ADH}$, or a direct inhibition of osmotic water flow in the collecting system, remains to be clarified. Whatever the exact interactions, the presence of ANP receptors on cultured tubular cells of the rabbit (41) and an ANP-induced rise in particulate guanylate cyclase and cyclic guanosine monophosphate in rat kidney tissue and in canine glomeruli, collecting duct, and ascending thick Henle's loop (56) are consistent with an influence of ANP on renal tissue at various levels.

\section{Acknowledgments}

The authors thank Dr. Claude Bachmann, Departement of Clinical Chemistry of the University of Berne, for performing and supervising 
the determinations of routine biochemistry and osmolality, and Mrs. M. Burkhalter, Mrs. K. Farina, Mrs. G. Haueter, Miss U. Laederach, Miss R. Mosimann, Miss E. Oldenberg, Miss A. Rohde, Mrs. H. Spalek, Miss R. Takkinen, and Miss B. von Gunten for their skilled technical assistance.

This study was supported in part by the Swiss National Science Foundation and a research grant from the CIBA-GEIGY Corporation, Basle, Switzerland.

\section{References}

1. De Bold, A. J., H. B. Borenstein, A. T. Veress, and H. Sonnenberg. 1981. A rapid and potent natriuretic response to intravenous injection of atrial myocardial extract in rats. Life Sci. 28:89-94.

2. Garcia, R., M. Cantin, G. Thibault, H. Ong, and J. Genest. 1982. Relationship of specific granules to the natriuretic and diuretic activity of rat atria. Experientia (Basel). 38:1071-1073.

3. Flynn, T. G., M. L. de Bold, and A. J. de Bold. 1983. The amino acid sequence of an atrial peptide with potent diuretic and natriuretic properties. Biochem. Biophys. Res. Commun. 117:859-865.

4. Thibault, G., R. Garcia, M. Cantin, and J. Genest. 1983. Atrial natriuretic factors: characterization and partial purification. Hypertension (Dallas). 5(Suppl. I):I-75-I-80.

5. Currie, M. G., D. M. Geller, B. R. Cole, J. G. Boylan, W. Yusheng, S. W. Holmberg, and P. Needleman. 1983. Bioactive cardiac substances: potent vasorelaxant activity in mammalian atria. Science (Wash. DC). 221:71-73.

6. Atlas, S. A., H. D. Kleinert, M. J. Camargo, A. Januszewicz, J. E. Sealey, J. H. Laragh, J. W. Schilling, J. A. Lewicki, L. K. Johnson, and T. Maack. 1984. Purification, sequencing and synthesis of natriuretic and vasoactive rat atrial peptide. Nature (Lond.). 309:717-719.

7. Kangawa, K., and H. Matsuo. 1984. Purification and complete amino acid sequence of alpha-human atrial natriuretic polypeptide (ahANP). Biochem. Biophys. Res. Commun. 118:131-139.

8. Kleinert, H. D., T. Maack, S. A. Atlas, A. Januszewicz, J. E. Sealey, and J. H. Laragh. 1984. Atrial natriuretic factor inhibits angiotensin-, norepinephrine- and potassium induced vascular contractility. Hypertension (Dallas). 6(Suppl. I):I-143-I-147.

9. Uehlinger, D. E., P. Weidmann, M. P. Gnädinger, and S. Shaw. 1985. Effects of human atrial natriuretic peptide on the pressor action of noradrenaline and angiotensin II in normal subjects. J. Hypertension (Lond.). 3(Suppl. 3):S319-S321.

10. Richards, A. M., M. G. Nicholls, H. Ikram, M. W. I. Webster, T. G. Yandle, and E. A. Espiner. 1985. Renal, hemodynamic and hormonal effects of human alpha atrial natriuretic peptide in healthy volunteers. Lancet. i:545-549.

11. De Bold, A. J. 1979. Heart atria granularity effects of changes in water-electrolyte balance. Proc. Soc. Exp. Biol. Med. 161:508-511.

12. Hirata, Y., M. Ganguli, L. Tobian, and J. Iwai. 1984. Dahl S rats have increased natriuretic factor in atria but are markedly hyporesponsive to it. Hypertension (Dallas). 6(Suppl. I):I-148-I-155.

13. Lang, R. E., H. Thölken, D. Ganten, F. C. Luft, H. Ruskoaho, and T. Unger. 1985. Atrial natriuretic factor-a circulating hormone stimulated by volume loading. Nature (Lond.). 314:264-266.

14. Briggs, J. P., B. Steipe, G. Schubert, and J. Schnermann. 1982. Micropuncture studies of the renal effects of atrial natriuretic substance. Pfluegers Arch. Eur. J. Physiol. 395:271-276.

15. Sonnenberg, H., W. A. Cupples, A. J. de Bold, and A. T. Veress. 1982. Intrarenal localization of the natriuretic effect of cardiac atrial extract. Can. J. Physiol. Pharmacol. 60:1149-1152.

16. Keeler, R. 1982. Atrial natriuretic factor has a direct prostaglandinindependent action on kidneys. Can. J. Physiol. Pharmacol. 60:10781082.

17. Nemeh, M. N., and J. P. Gilmore. 1983. Natriuretic activity of human and monkey atria. Circ. Res. 53:420-423.

18. Pollock, D. M., and R. O. Banks. 1983. Effect of atrial extract on renal function in the rat. Clin. Sci. (Lond.). 65:47-55.

19. Baines, A. D., A. J. de Bold, and H. Sonnenberg. 1983. Natriuretic effect of atrial extract on isolated perfused kidney. Can. J. Physiol. Pharmacol. 61:1462-1466.
20. Camargo, M. J. F., H. D. Kleinert, S. A. Atlas, J. E. Sealey, J. H. Laragh, and T. Maack. 1984. Ca-dependent hemodynamic and natriuretic effects of atrial extract in isolated rat kidney. Am. J. Physiol. 246(Renal Fluid Electrolyte Physiol. 15):F447-F456.

21. Maack, T., D. N. Marion, M. J. F. Camargo, H. D. Kleinert, J. H. Laragh, E. D. Vaughan, Jr., and S. A. Atlas. 1984. Effects of auriculin (atrial natriuretic factor) on blood pressure, renal function, and the reninaldosterone system in dogs. Am. J. Med. 77:1069-1075.

22. Beasley, D., and R. L. Malvin. 1985. Atrial extracts increase glomerular filtration rate in vivo. Am. J. Physiol. 248(Renal Fluid Electrolyte Physiol. 17):F24-F30.

23. Huang, C. L., J. Lewicki, L. K. Johnson, and M. G. Cogan. 1985. Renal mechanism of action of rat atrial natriuretic factor. J. Clin. Invest. 75:769-773.

24. Seymour, A. A., E. H. Blaine, E. K. Mazack, S. G. Smith, I. I. Stabilito, A. B. Haley, M. A. Napier, M. A. Whinnery, and R. F. Nutt. 1985. Renal and systemic effects of synthetic atrial natriuretic factor. Life Sci. 36:33-44.

25. Borenstein, H. P., W. A. Cupples, H. Sonnenberg, and A. T. Veress. 1983. The effect of a natriuretic atrial extract on renal hemodynamics and urinary excretion in anesthetized rats. J. Physiol. (Lond.). 334:133-140.

26. Ishihara, T., K. Aisaka, K. Hattori, S. Hamasaki, M. Morita, T. Noguchi, K. Kangawa, and H. Matsuo. 1985. Vasodilatory and diuretic actions of $\alpha$-human atrial natriuretic polypeptide. Life Sci. 36:12051215.

27. Weidmann, P., C. Beretta-Piccoli, W. H. Ziegler, G. Keusch, Z. Glück, and F. C. Reubi. 1978. Age versus urinary sodium for judging renin, aldosterone and catecholamine levels: studies in normal subjects and patients with essential hypertension levels. Kidney Int. 14:619-628.

28. Reubi, F. C. 1982. Nierenkrankheiten. Hans Huber AG, Bern. Third ed. 85-98.

29. Sealey, J. E., J. Gerten-Banes, and J. H. Laragh. 1972. The renin system: variations in man measured by radioimmunoassay. Kidney Int. 1:240-253.

30. Düsterdieck, G., and G. Mc Elwee. 1971. Estimation of angiotensin II concentration in human plasma by radioimmunoassay. Some applications to physiological and clinical states. Eur. J. Clin. Invest. 2: 32-38.

31. Malvano, R., C. Gandolf, D. Giannesi, P. Gianotti, and P. Grosso. 1976. Radioimmunoassay of aldosterone in crude plasma extracts. $J$. Nucl. Biol. Med. 20:37-44.

32. Weidmann, P., C. Beretta-Piccoli, L. Link, M. G. Bianchetti, K. Boehringer, and J. J. Morton. 1983. Cardiovascular counterregulation during sympathetic inhibition in normal subjects and patients with mild hypertension. Hypertension (Dallas). 5:873-880.

33. Smedes, F., J. C. Kraak, and H. Poppe. 1982. Simple and fast solvent extraction system for selective and quantitative isolation of adrenaline, noradrenaline and dopamine from plasma and urine. J. Chromatogr. 231:25-39.

34. Rascher, W., R. E. Lang, T. Unger, D. Ganten, and F. Gross. 1982. Vasopressin in brain of spontaneously hypertensive rats. Am. J. Physiol. 242:H496-H499.

35. Currie, M. G., D. M. Geller, B. R. Cole, N. R. Siegel, K. K. Fok, S. P. Adams, S. R. Eubanks, G. R. Galluppi, and P. Needleman. 1984. Atriopeptins: bioactive peptides derived from mammalian cardiac atria. J. Hypertension (Lond.). 2(Suppl. 3):309-312.

36. Nakao, K., A. Sugawara, N. Morii, M. Sakamoto, M. Suda, J. Soneda, T. Ban, M. Kihara, Y. Yamori, M. Shimokura, Y. Kiso, and H. Imura. 1984. Radioimmunoassay for $\alpha$-human and rat atrial natriuretic polypeptide. Biochem. Biophys. Res. Commun. 124:815-821.

37. Tanaka, I., K. S. Misono, and T. Inagami. 1984. Atrial natriuretic factor in rat hypothalamus, atria and plasma: determination by specific radioimmunoassay. Biochem. Biophys. Res. Commun. 124:663-668.

38. Jacobowitz, D. M., G. Skofitsch, H. R. Keiser, R. L. Eskay, and N. Zamir. 1985. Evidence for the existence of atrial natriuretic factorcontaining neurons in the rat brain. Neuroendocrinology. 40:92-94.

39. Ackermann, U., T. G. Irizawa, S. Milojevic, and H. Sonnenberg. 
1984. Cardiovascular effects of atrial extracts in anesthetized rats. Can. J. Physiol. Pharmacol. 62:819-826.

40. Hirata, Y., M. Tomita, H. Yoshimi, and M. Ikeda. 1984. Specific receptors for atrial natriuretic factor (ANF) in cultured vascular smooth muscle cells of rat aorta. Biochem. Biophys. Res. Commun. 125:562568.

41. Napier, M. A., R. L. Vandlen, G. Albers-Schönberg, R. F. Nutt, S. Brady, T. Lyle, R. Winquist, E. P. Faison, L. A. Heinel, and E. H. Blaine. 1984. Specific membrane receptors for atrial natriuretic factor in renal and vascular tissues. Proc. Natl. Acad. Sci. USA. 81:5946-5950.

42. Winquist, R. J., E. P. Faison, S. A. Waldman, K. Schwartz, F. Murad, and R. M. Rapoport. 1984. Atrial natriuretic factor elicits an endothelium-independent relaxation and activates particulate guanylate cyclase in vascular smooth muscle. Proc. Natl. Acad. Sci. USA. 81:76617664.

43. Garcia, R., G. Thibault, M. Cantin, and J. Genest. 1984. Effect of a purified atrial natriuretic factor on rat and rabbit vascular strips and vascular beds. Am. J. Physiol. 247(Regulatory Integrative Comp. Physiol. 16):R34-R39.

44. Winquist, R. J., E. P. Faison, E. P. Baskin, P. B. Bunting, R. F. Nutt, and L. T. Callahan III. 1984. Characterization of synthetic atrial natriuretic factor: vasodilator profile and decreased vascular sensitivity in hypertensive rats. J. Hypertension (Lond.). 2(Suppl. 3):325-327.

45. Tang, J., R. J. Webber, D. Chang, J. K. Chang, J. Kiang, and E. T. Wei. 1984. Depressor and natriuretic activities of several atrial peptides. Regul. Pept. 9:53-59.

46. Keeler, R., and A. M. Azzarolo. 1983. Effects of atrial natriuretic factor on renal handling of water and electrolytes in rats. Can. J. Physiol. Pharmacol. 61:996-1002.

47. Burnett, J. C., Jr., J. P. Granger, and T. J. Opgenorth. 1984. Effects of synthetic atrial natriuretic factor on renal function and renin release. Am. J. Physiol. 247(Renal Fluid Electrolyte Physiol. 16):F863F866.

48. Ichikawa, I., B. R. Dunn, J. L. Troy, T. Maack, and B. M. Brenner. 1985. Influence of atrial natriuretic peptide on glomerular microcirculation in vivo. Clin. Res. 33:487a. (Abstr.)

49. Fried, T. A., R. N. McCoy, R. W. Osgood, H. J. Reineck, and J. Stein. 1985. The effect of atrial natriuretic peptide on glomerular hemodynamics. Clin. Res. 33:584a. (Abstr.)

50. Johannesen, J., M. Lie, and F. Kiil. 1977. Effect of glycine and glucagon on glomerular filtration and renal metabolic rates. Am. J. Physiol. 233:F61-F66.

51. Atarashi, K., P. J. Mulrow, R. Franco-Saenz, R. Snajdar, and J. Rapp. 1984. Inhibition of aldosterone production by an atrial extract. Science (Wash. DC). 224:992-994.

52. Goodfriend, T. L., M. E. Elliott, and S. A. Atlas. 1984. Actions of synthetic atrial natriuretic factor on bovine adrenal glomerulosa. Life Sci. 35:1675-1682.

53. Hathaway, S., and S. Solomon. 1984. The effect of 6-hydroxydopamine on the renal responses to atrial natriuretic extract and blood volume expansion. Proc. West. Pharmacol. Soc. 27:89-93.

54. Ishii, M., T. Sugimoto, T. Kobayashi, Y. Uehara, Y. Hirata, H. Matsuoka, T. Ikeda, and T. Sugimoto. 1984. The effects of atrial extract on blood pressure and urinary excretion of electrolytes and prostaglandin $\mathrm{E}_{2}$ in rats. Prostaglandins Leukotrienes Med. 16:325-332.

55. Thibault, G., R. Garcia, M. Cantin, and J. Genest. 1984. Atrial natriuretic factor and urinary kallikrein in the rat: antagonistic factors? Can. J. Physiol. Pharmacol. 62:645-649.

56. Tremblay, J., R. Gerzer, P. Vinay, S. C. Pang, R. Béliveau, and P. Hamet. 1985. The increase in cGMP by atrial natriuretic factor correlates with the distribution of particulate guanylate cyclase. FEBS (Fed. Eur. Biochem. Soc.) Lett. 181:17-22. 